\title{
ANALISA RUH PENDIDIKAN KARAKTER \\ DALAM PENDIDIKAN NASIONAL (UNDANG-UNDANG 2003)
}

\author{
Syahrul Akmal Latif dan Yusri Herman
}

\begin{abstract}
The issue of education is never over to talk about because education is one measurement of a person's individual accomplishments and achievements systematically nation. The high education of human resources will give a lot of useful works for the individual and social. Unfortunately, the education that was developed based on this character only strengthen individual and social, it's beyond the divine value. It is due to the historical roots of the character education by Immanuel Kant (1724-1804) and Charles Renouvier (1815-1857); Religious morality in the low education and August Comter (17981857); secular morality. Renouvier said the weakness of youth responsibility, loss of justice equality, respect and others. The process of character education is faced with the application of secularization. Such as, in France Francois Camille Jules Ferry (1832-1893) , a French Education minister said; Moral education is important but explicitely teaching morality does not needed. The development of character education in America is very dynamic. It's started from $19^{\text {th }}$ century (1900-1950) until 1997.It's established nationally. Finally, Thomas lichona explained the entire role of religion in the education of character with seven steps and the role of teachers in character education. Thus, the author conducted religious analysis which widely spread among society is that the teaching of Protestant religious. But, It successfully gives individual and social value as character education. On the contrary, the goal of our national educational in 1945 (Version amendment) Article 31, paragraph 3 states: The Government shall manage and organize a national education system. Which increases the Faith and piety as well as noble character in order to educate the nation that adopted by law. Article 31, paragraph 5, states that the government advances science and technology to uphold the values of religious and national unity for the progress of civilization and prosperity of mankind. Likewise, the purpose of philosophy Nasionsl Education Act No. 20 of 2003. The 1945 Constitution and the Law NO 20 of 2003

Strongly reflects the value of belief in one God as the first principle of Pancasila as the first principle says it is an acknowledgment that in developing the nation's education should not be separated from human relations and slave relationship with God the creator.
\end{abstract}

Key Word : Character, Study

\section{PENDAHULUAN}

Untuk kesekian kali dunia pendidikan kita menjadi yang tertuduh atas kebobrokan bangsa. Dari berbagai peristiwa saat ini, mulai dari kasus Gayus Tambunan, Nazaruddin, Makam Periok, tawuran antar pelajar bahkan antar mahasiswa cukup menjadi bukti atas runtuhnyapotensi bangsa Indonesia atau dengan bahasa yang agak kasar "kebobrokan bangsa". Peristiwa lain yang membuktikan atas kebobrokan ini misalnya berbagai macam psikotropika dan narkotika banyak beredar di kalangan anak sekolah. Lebih mengerikan, penjual dan pembeli adalah orang-orang yang masih berstatus siswa. Mereka menjadi pengguna sekaligus pengedar.
Fenomena tersebut seolah memantapkan hasil survei PERC ( Political and Economic Risk Colsultancy) dan UNDP ( United Nations Developmen Program ). PERC menyebutkan bahwa sistem Vietnam (dari 12 negara yang disurvei). Sementara itu laporan UNDP tahun 2004 pendidikan di Indonesia menempati posisi terburuk di kawasan Asia, satu tingkat di bawah dan 2005 menyatakan bahwa IPM (indeks pembangunan manusia) di Indonesia juga menempati posisi terburuk. Tahun 2004 Indonesia menempati urutan 111 dari 175 negara dan tahun 2005 menempati urutan 110 dari 177 negara. 
Litbang kompas juga menyebutkan data dan fakta bahwa 158 kepala daerah tersangkut korupsi sepanjang 2004-2011, 42 anggota DPR terseret korupsi pada kurun waktu 2008-2011, 30 anggota DPR periode 1999-2004 terlibat kasus suap pemilihan DGS BI dan Kasus korupsi terjadi diberbagai lembaga seperti KPU, KY, KPPU, Ditjen Pajak, BI, dan BKPM.

Inilah pertanyaan awal dari ECT (Educational Childhood Today) kepada Thomas Lickona. Pakar psikologi perkembangan anak pada University New York di Cortland ini menjelaskan bahwa dewasa ini peradaban manusia telah mengalami kemunduran sejalan dengan adanya kemunduran karakter generasi muda kita. Tentu saja, hal ini menjadi salah satu tanggung jawab orang dewasa untuk keberlanjutan perababan bangsa tersebut, tidak lain dengan cara mewariskan nila-nilai kebajikan bagi masyarakat, khususnya kepada anak-anak dan generasi mudanya.

Hal demikian ternyata juga berlaku di negara kita tercinta Indonesia. Dalam karya tulisnya bertajuk "Restorasi Keberadaban Bangsa Melalui Pendidikan Karakter”, Ir. Sutawi, M. P, dosen Universitas Muhammadiyah Malang, telah mengutip pendapat seorang ahli Amerika, Thomas Lickona, bahwa ada 10 aspek degradasi moral yang melanda suatu negara yang merupakan tanda-tanda kehancuran suatu bangsa. Kesepuluh tanda tersebut antara lain meningkatnya kekerasan pada remaja, penggunaan kata-kata yang memburuk, pengaruh peer group (rekan kelompok) yang kuat dalam tindak kekerasan, meningkatnya penggunaan narkoba, alkohol dan seks bebas, kaburnya batasan moral baik-buruk, menurunnya etos kerja, rendahnya rasa hormat kepada orang tua dan guru, rendahnya rasa tanggung jawab individu dan warga negara, membudayanya ketidakjujuran, serta adanya saling curiga dan kebencian diantara sesama.

Karya tulis Sutawi tersebut telah memenangkan lomba karya tulis tentang Pendidikan Karakter yang diselenggarakan oleh Pusat Informasi dan Hukum, Kementerian Pendidikan Nasional, dengan memperoleh penghargaan dan hadiah Rp10 juta dari Mendiknas. Dalam artikel itu, Sutawi mengungkapkan degradasi karakter yang terjadi di suatu bangsa dan negara, terutama yang terjadi di Indonesia.

Menurut Sutawi, saat ini bangsa Indonesia sudah menunjukkan kesepuluh tanda tersebut. Hal ini dinilai perlu untuk segera diperbaiki sebelum bangsa ini benar-benar hancur. "Agenda utama bangsa Indonesia mendatang adalah melakukan restorasi keberadaban bangsa melalui pendidikan karakter. Pendidikan karakter yang dapat dimaknai sebagai sebuah proses pananaman nilai untuk membantu siswa menjadi cerdas dan baik (smart and good) pada tiga aspek yang meliputi kognitif (head) afektif (heart), dan psikomotorik (hand).

Mengingat pentingnya pendidikan budaya dan karakter bangsa tersebut, maka konsep pendidikan karakter harus menjadi ruh dari pembangunan bangsa dan negara kita. Untuk itu, maka konsep besar pendidikan karakter harus segera dirumuskan menjadi program dan kegiatan yang operasional untuk dapat dilaksanakan dalam kehidupan berbangsa dan bernegara mulai saat ini dan masa depan. 


\section{Tujuan Pendidikan Nasional}

Tujuan Pendidikan Nasional adalah mencerdaskan kehidupan bangsa dan mengembangkan manusia Indoensia seutuhnya, yaitu manusia yang beriman dan bertaqwa terhadap Tuhan Yang Maha Esa dan berbudi pekerti luhur, memiliki pengetahuan dan keterampilan, kesehatan jasmani dan rohani, kepribadian yang mantap dan mandiri serta rasa tanggung jawab kemasyarakatan dan kebangsaan.

Dengan adanya pendidikan, maka akan timbul dalam diri seseorang untuk berlombalomba dan memotivasi diri kita untuk lebih baik dalam segala aspek kehidupan. Pendidikan merupakan salah satu syarat untuk lebih memajukan pemrintah ini, maka usahakan pendidikan mulai dari tingkat SD sampai pendidikan di tingkat Universitas.

Pada intinya pendidikan itu bertujuan untuk membentuk karakter seseorang yang beriman dan bertakwa kepada Tuhan Yang Maha Esa. Akan tetapi disini pendidikan hanya menekankan pada intelektual saja, dengan bukti bahwa adanya UN sebagai tolak ukur keberhasilan pendidikan tanpa melihat proses pembentukan karakter dan budi pekerti anak.

\section{Tujuan Pendidikan Nasional dalam UUD 1945 (versi Amandemen)}

- Pasal 31, ayat 3 menyebutkan, "Pemerintah mengusahakan dan menyelenggarakan satu sistem pendidikan nasional, yang meningkatkan keimanan dan ketakwaan serta ahlak mulia dalam rangka mencerdaskan kehidupan bangsa, yang diatur dengan undang-undang.,
- Pasal 31, ayat 5 menyebutkan, "Pemerintah memajukan ilmu pengetahuan dan teknologi dengan menunjang tinggi nilai-nilai agama dan persatuan bangsa untuk kemajuan peradaban serta kesejahteraan umat manusia."

Tujuan Pendidikan Nasional dalam UndangUndang No. 20, Tahun 2003

Jabaran UUD 1945 tentang pendidikan dituangkan dalam Undang-Undang No. 20, Tahun 2003. Pasal 3 menyebutkan, "Pendidikan nasional berfungsi mengembangkan kemampuan dan membentuk watak serta peradaban bangsa yang bermartabat dalam rangka mencerdaskan kehidupan bangsa, bertujuan untuk berkembangnya potensi peserta didik agar menjadi manusia yang beriman dan bertakwa kepada Tuhan Yang Maha Esa, berakhlak mulia, sehat, berilmu, cakap, kreatif, mandiri, dan menjadi warga negara yang demokratis serta bertanggung jawab."

\section{Tujuan Pendidikan Menurut UNESCO}

Dalam upaya meningkatkan kualitas suatu bangsa, tidak ada cara lain kecuali melalui peningkatan mutu pendidikan. Berangkat dari pemikiran itu, Perserikatan Bangsa-Bangsa (PBB) melalui lembaga UNESCO (United Nations, Educational, Scientific and Cultural Organization) mencanangkan empat pilar pendidikan baik untuk masa sekarang maupun masa depan, yakni:

(1) learning to Know

(2) learning to do

(3) learning to be

(4) learning to live together. 
Dimana keempat pilar pendidikan tersebut menggabungkan tujuan-tujuan IQ, EQ dan SQ.

Bahkan dari sumber yang lain disebutkan bahwa:

"Character education is the deliberate effort to cultivate virtue - that is objectively good human qualities that are good for the individual person and good for the whole society"

"Pendidikan karakter adalah usaha sengaja (sadar) untuk mewujudkan kebajikan - yaitu kualitas kemanusian yang baik secara obyektif, bukan hanya baik untuk individu perseorangan, tetapi juga baik untuk masyarakat secara keseluruhan".

Dengan demikian, proses pendidikan karakter, ataupun pendidikan akhlak dan karakter bangsa sudah tentu harus dipandang sebagai usaha sadar dan terencana, bukan usaha yangsifatnya terjadi secara kebetulan. Dengan kata lain, pendidikan karakter adalah usaha yang sungguh-sungguh untuk memahami, membentuk, memupuk nilai-nilai etika, baik untuk diri sendiri maupun untuk semua warga masyarakat atau warga negara secara keseluruhan.

Berkenaan dengan pentingnya pendidikan ini, kita diingatkan bahwa "Education comes from within; you get it by struggle and effort and thought" (Napoleon Hill). Pendidikan datang dari dalam diri kita sendiri, kita memperolehnya dengan perjuangan, usaha, dan berfikir.

\section{Akar Sejarah}

1. Immanuel kant 91724-18040 dan Charles Renouvier (1815-1903): moralitas religius dalam pendidikan

2. August Comte (1798-1857): Moralitas sekular

\section{Pendidikan Moral Religius}

1. Renouvier: melemahnya rasa tanggung jawab pemuda, hilangnya keadilan, kesetaraan, rasa hormat dll = pelajar melakukan tindakan tercela dan mencapai prestasi akademik yang dapat diterima secara sosial

2. Hal ini mengharuskan agar pendidikan mencakup unsur-unsur moral : agar pelajar bisa memahami dan mempraktikkan bukan hanya (a) bagaimana membuat keputusan etis, tapi juga (b) kewajiban-kewajiban etika sosial

\section{Sekularisasi}

- Jules francois Camille Feryy (1832-1893) (menteri pendidikan prancis): pendidikan moral penting, tapi pengajaran moralitas relijius secara terbuka tidak perlu=moralitas modern $=$ II pendidikan mengatur bahwa moralitas diajarkan sebagai subjek terpisah yang berisi tentang kewajiban-kewajiban terhadap diri sendiri,keluarga, manusia dan Tuhan.

- Kepercayaan dan pemahamaan universal mengenai moralitas manusia, yang melintasi doktrin agama tertentu dan mencakup beragam tradisi keagamaan.

- Agama dari (baca: kristen) tidak lagi mencakup semua aspek dan pengajaran moral bergeser dari sumber relegius pada guru yang sekular

- Moralitas yang didasarkan atas tipologisasi perkembangan masyarakat ala comte: relejius-metafisis-positif.

- Penanaman moral yang didasarkan atas metode saintifik dan filsafat modern 


\section{Sekularisasi di Amerika}

- $1776 \quad 100 \%$ kandungan buku teks sekolah di Amerika bersifat relejius dan moral

- $1776-1825=$ peningkatan jumlah imigran $=$ sekularisasi pendidikan= sekolah menerapkan sistem nilai yang sama dengan pabrik.

- $1870=$ sekolah gratis dengan biaya pajak=UU pelanggaran Bibel dari kelas sekolah umum.

\section{Pendidikan karakter di Amerika (abad 19)}

- John Heyl Vincent (1832-1920): perkembangan karakter terjadi diberbagai tempat sepanjang hidup seseorang.

- Rumah dan sekolah saling mempengaruhi pada pembetukan karakter selama 20 tahun pertama kehidupan seseorang.

- Karena itu, guru dan orang tua karakter moral yang baik untuk dapat mengajarkan karakter moral yang baik pula

Pendidikan Karakter di Amerika (19001950)

- 1916, William Hutchins: panduan moral anak=kontrol-diri, sehat, sopan, jujur, sportif, kerjasama, mandiri, cekatan, tanggung jawab, dan terampil.

- Hartshorne dan may - berdasarkan penelitian dari tahun 1924-1929 rehadap 10.865 siswa kelas 5 sampai 8 di 23 komunitas di amerikamenyimpulkan bahwa pendidikan moral- sekular dan relejius -tidak berdampak perilaku siswa.
Pendidikan karakter di Amerika (1900-1950)

(Reaksi terhadap penelitian Hartshorne \& May)

- Membuktikan kesalahan ide mengenai karakter dan, karena itu, pendidikan karakter

- Antara 1930-1940 penggunaan kata karakter turun $85 \%$.

- Artikel tentang pendidikan karakter turun dari 480 pada $1929-1938$ menjadi 115 pada $1939-1948$-penurunan $76 \%$

- Pendidikan karakter langsung hampir hilang di tahun 1950-an

- Leming menyatakan bahwa implikasi dari penelitian Hartshorne \& May adalah bahwa pendidikan yang ada perlu dibenahi dengan mengurangi focus pada metode langsung, seperti ceramah, dan menekankan pada metode tidak langsung, seperti menciptakan ingkungan sekolah yang posistif dan mengadakan aktivitas yang berorientasi pada pelayanan untuk para siswa. ${ }^{19}$

Perkembangan pendidikan karakter di Amerika (1950-1997)

$\square$ John Dewey (1859-1952) pada 1964 mengkritik kecenderungan sekolah untuk memisahkan pengajaran ilmu dan penumbuhan karakter.

$\square$ Lawrence Kohlberg (1927-1952) memformulasikan 4 tahap perkembangan moral: (a) hadiah dan hukuman; (b) perhatian pada

\footnotetext{
${ }^{19}$ Jame S. Leming (2008), “Theory. Research, and Practise In The Twentieth Century Character Education Movement", Journal Of Reseach in Character Education,6(2), hlm.17-36
} 
kebutuhan diri dan orang lain;(c) menyenangkan atau membantu orang lain dan melakukan kewajiban dan menghrmati otoritas;(e) pendapat dan nilai pribadi;(f) kesadaran individu;(g) penghormatan terhadap setiap jiwa manusia. Peningkatan dari satu tahap ke yang lain dicapai melaluhi diskusi rasional.

\section{Peran Agama dalam pendidikan Karakter}

Thomas Lickona menyarankan tujuh langkah agar agama berperan dalam pendidikan karakter.

1. Siswa diberi penjeasan mengenai pondasi relejius dari pendirian bangsa.

2. Siswa diajarkan bahwa setiap gerakan reformasi sosial penting selalu dilandasi oleh agama.

3. Siswa dididik dengan ceria tentang peran motivasi relijius dalam kehidupan individual, masa lalu atau sekarang.

4. Kurikulum disusun dengan mencakup agama.

5. Siswa didorong untuk menggunakan latar belakang kulturalnya (termasuk agama) ketika mereka mendidkusikan persoalan-persoalan sosial dan membuat kebenaran moral.

6. Guru dapat menggunakan agama untuk mendiskusikan pertan

7. Guru dapat mendrng murid untuk mengembangkan visi kehidupan mengenai pertanyaan-pertanyaan mendasar dalam kehidupan. ${ }^{20}$

20 .., (1999), "Relegion and Character Education", The Phi Delta Kappa,81(1), hlm. 21-24, 26-27
Perkembangan pendidikan karakter di Amerika (1950-1997) ${ }^{21}$

- Pada 1968, Character Education Institute of San Antonio mengembangkan kurikulum pendidikan karakter untuk tingkat taman kanak-kanak sampai kelas lima. Pada 1984, ditambahkan kurikulum untuk kelas 6 pada 1985 kurikulum untuk kelas 7,8 dan 9.

- Tujuan dari kurikulum ini adalah untuk melahirkan warga negara yang bertanggung jawab.

- Pada 1985, Chicago Fondation For Education didirikan untuk memenuhi kebutuhan siswa di sekolah public di Chicago dan membuat kurikulum pendidikan karakter untuk diimplementasikan dilebih dari 60000 kelas.

\section{Peran Guru dalam pendidikan Karakter}

Thomas Lichona mengusulkan beberapa hal berikut untuk meningkatkan peran guru dalam pendidikan karakter.

1. Memahami pendidikan karakter sebagai usaha sadar untuk menanamkann kebaikan (pengertahuan moral,[perasan moral dan perilaku moral)

2. Guru sebagai penjaga ,mdel dan mentor bagi moralitas murid yang biasanya adalahg hubungan yang berkualitas dengan mereka

3. Menciptakan kmunitas dalam kelas yang peduli antar murid.

\footnotetext{
${ }^{21}$ Thomas Lickona,(1997), “"The Teacher's Role In character Education " , journal of Education, 179 (2), HIm. 63-80
} 
4. Menegakkan disiplin moral.

5. Menciptakan lingkungan kelas yang demokratis.

6. Mengajarkan nilai-nilai melaluhi kurikulum.

7. Pembelajaran kooperatif.

8. Menanamkan sadar karya (conscience of craft), kemampuan merasa puas atas pekerjaan yang dilakukan dengan baik dan merasa malu atas karya yang kurang baik,

9. Membiasakan refleksi etis

10. Mengajarkan reslusi konflik tanpa paksaan dan intimidasi. ${ }^{22}$

Pearson dan Nichlson mengusulkan beberapa hal berikut ini untuk meningkatkan dalam pendidikan karakter.

1. Mengembangkan aturan kelas yang disepakati bersama.

2. Menggunakan bahasa positif.

3. Menjelaskan konsekuensi tindakan siswa

4. Menjelaskan karakter positif dan maknanya bagi siswa

5. Mendorong kerjasama.

6. Menyediakan waktu untuk menginspirasi.

7. Menunjuk mentor siswa baru dari kalangan siswa.

8. Menganjurkan penulisan jurnal untuk menjadi bahan refleksi siswa.

9. Mendiskusikan persalan berdasar literatur

${ }^{22}$ Thomas Lickona,(1997), “ The Teacher's Role In character Education " , journal of Education, 179 (2), HIm. 63-80

\section{Tinjauan Islam terhadap Pendidikan}

\section{Karakter}

Diskursus pendidikan karakter ini memberikan pesan bahwa spiritualitas dan nilainilai agama tidak dapat dipisahkan dengan pendidikan karakter. Moral dan nilai spiritual sangat fundamental dalam membangun kesejahteraan organisasi sosial manapun. Tanpa keduanya maka elemen vital yang mengikat khidupan masyarakat dapat lenyap. Dalam Islam terdapat nilai utama, yaitu akhlak, adab dan keteladanan.

Akhlak diartikan sebagai ilmu tata karma, ilmu yang berusaha mengena tingkah laku manusia, kemudian memberi nilai kepada perbuatan baik atau buruk sesuai dengan normanorma dan tata susila.

Kualitas akhlak seseorang setidaknya dapat dilihat dari Aqidah Islam. Aqidah Islam adalah aqidah yang dibawa oleh utusan-utusan Allah dan telah dijelaskan dalam kitab-kitab yang Allah turunkan dan diwajibkan kepada semua manusia dan jin. Aqidah menurut Islam ialah beriman kepada Allah yaitu, keyakinan yang terikat erat dalam hati bahwa Allah adalah penguasa segala sesuatu dan pemiliknya.

Dalam beriman kepada kita harus mempelajari tentang Tauhid. Ada tiga macam Tauhid : Tauhid Rububiyyah. Tauhid Uluhiyah dan Asma Wassifat

1. Tauhid Rububiyah

Adalah pengakuan bahwa Allah satusatunya Tuhan yang menciptakan alam, yang memelihara dan mengatur, yang menghidupkan dan mematikan, yang memberi rizki dan memiliki kekuatan 
tak terbatas.Sebagaimana firman Allah dalam surah Az-Zukhruf(43) ayat 87 :

"Dan sesungguhnya jika kamu bertanya kepada mereka, "Siapakah yang menciptakan mereka”, niscaya mereka menjawab, “Allah”. Maka bagaimanakah mereka dipalingkan(dari menyembah Allah)?" (QS 43:87)

2. Tauhid Uluhiyah

Ialah mengesakan Allah dalam perbuatan seorang hamba

إفراد الله تعالى بأفعال العباد

Ini bermakna : semua perbuatan seseorang baik yang didorong kepercayaan gaib atau kebutuhan lahir harus ditunjukan dan disandarkan kepada Allah saja. Apabila ada perbuatan yang didorong kepercayaan gaib ditunjukkan kepada selain Allah, maka itu disebut syirik Akbar.

3. Tauhid Asma dan sifat Allah adalah menetapkan nama dan sifat yangtelah Allah tetapkan atas dirinya didala Al-Quran dan dijelaskan dalam hadist

\section{Asas Pendidikan Islam}

Salah satu cara al-Qur'an menekankan pentingnya sesuatu agar diingat oleh pembacanya adalah dengan tiga kata-kata : Allah, Rabb dan 'Ilmu. Allah disebut sebanyak 2800 kali, Rabb disebut sebanyak 950 kali dan 'Ilmu disebut sebanyak 750 kali. Ketiga kata tersebut saling berkaitan satu sama lain membentuk apa yang dinamakan pendidikan Islam. Beriman kepada Allah misalnya dan berilmu meninggikan derajat orang-orang yng beriman dan berilmu pengetahuan dengan derajat yang setinggi-tingginya (QS $58: 11$ ).

Orang yang berilmupun dibedakan dari orang-orang yang tidak berilmu : "Katakanlah : Adakah orang yang berakallah yan dapat menerima pelajaran.” (QS 39 : 9).

Hubungan ilmu dengan Allah juga erat sebab Allah adalah Maha Berilmu, sehingga manusia diajari agar meminta (berdoa) kepada Allah agar tambah ilmunya : “Ya Allah, tambahkanlah ilmuku” (QS 20 : 11). Nabi Saw juga bersabda, "Barangsiapa tambah ilmunya tapi tidak tambah petunjuknya, tidak akan tambah dari Allah kecuali jauhnya." (al-Hadits). Ini berarti ilmu berperan besar dalam menambah iman dan keimanan kepada Allah dapat pula menambah ilmu pada seseorang. Bahkan, dalam hadits lain dinyatakan bahwa “ Barangsiapa mengajarkan sesuatu ilmu maka Allah akan mengajarinya ilmu yang belum diketahuinya." (al-Hadits)

Dari pemahaman terhadap berbagai konsep seminal yang terdapat al-Qur'an untuk Islam kemudian menghasilkan istilah keilmuan (saintific term/vocabulary) yang khusus tentang pendidikan. Tiga istilah yang muncul dari pemahaman dan pengamalan terhadap al-Qur'an adalah pertama ta'lim yaitu proses transformasi ilmu melalui pengajaran; Kedua tarbiyah yaitu istilah yang berasal dari kata rabba artinya meningkatkan, menumbuhkan atau mendidik dan ketiga adalah takdib yaitu dari kata addaba yang berarti menanamkan adab yang terdiri dari ilmu dan akhlak. Meski istilah tersebut digunakan secara bereda-beda namun intinya pendidikan Islam itu berangkat dari konsep manusia sebagai subyek pemberi dan penerima 
ilmu. Ilmu sebagai materi yang ditransformasikan dan adab atau akhlak adalah produk dari proses tersebut.

Pengamalan dari ketiga istilah keilmuan terssebut di atas, dapat disaksikan dalam pentas sejarah umat islam. Al-Qur'an merupakan sumber ilmu pengetahuan yang menjadi pusat pembelajaran. Apa yang diajarkan adalah ilmu yang mengajar disebut mualim dan produk dari pengajaran ini adalah seorang yang alim artinya yang memiliki ilmu. Allah sendiri mensifati diriNya dengan al-'Alim atau Maha Mengetahui. Ini semua menunjukkan bahwa medan makna 'ilmu dalam Islam berkaitan keimanan kepada Allah, amal dan akhlak.

Maka dari itu, tujuan Pendidikan Islam tidak saja sebatas penguasaan bidang keilmuan tertentu saja tetapi juga aspek-aspek lain dalam diri manusia secara menyeluruh. Tujuan yang akan dipakai adalah menghasilkan manusia yang sempurna (insan kamil) termasuk akalnya, jiwanya dan aspek-aspek sosialnya.

Al-Attas menegaskan bahwa : ...the comprehensive and integrated approach to education in Islam is directed toward the "balanced growth of the total personality...through training man's spirit, intellect, rational self, feelings and bodily senses...such that faith is infused into the whole of his personality.

Terjemahan bebasnya adalah pendekatan yang konprehensif dan integral terhadap pendidikan Islam harus ditunjukkan untuk menumbuh kembangkan pribadi siswa secara total dan seimbang melaui pelatihan jiwa, intelek, jiwa yang rasional, perasaan dan panca indra dengan sedemikan rupa sehingga keimanan dapat merasuk ke dalam keseluruhan pribadinya. ${ }^{23}$

Sejalan dengan al-Attas, Second World Comference on Muslim Education menetapkan tujuan pendidikan Islam sebagai berikut : education should aim at the balance growth of total personality of man through the training of man's spirit, intellect, the rational self, feeling and bodily sense. Education should therefore cater for the growth of man in all his aspect, spiritual, intellectual, imaginative, physical, scientific, linguistic, both individually and collectively and motivate all these aspect towards goodness and attainment of perfection. The ultimate aim of education lies in the realization of complete submission to Allah on the level of individual, the community and humanity at large.

Terjemahan bebasnya, pendidikan harus bertujuan untuk mengembangkan pribadi manusia secara seimbang dan total melalui pelatihan jiwa, intelek, diri yang rasional, perasaan dan panca indra. Maka dari itu, pendidikan harus memberi (kesempatan) manusia untuk berkembang dalam semua aspeknya, spiritual, intelektual, imajinasi, phisik, keilmuan, linguistic, baik individu maupun kelompok dan memberi motivasi agar semua aspek ini mengarah ke kebaikan dan pencapaian pada kesempurnaan. Tujuan akhir dari pendidikan adalah realisasi dari penyerahan diri kepada Allah pada tingkat individu, komunitas dan kemanusiaan secara umum. Jika dalam komferensi itu dinyatakan bahwa tujuan

\footnotetext{
${ }^{23}$. Al-Attas, Syed Muhammad Al-Naquib. 1979. Aims and Objective of Islamic Education. Jeddah, Saudi Arabia : Hodder and Stoughton, hal. 158 (ISLAMIA, VOLUME 1X, No 1,2014.)
} 
akhir dari Pendidikan Islam adalah untuk penyerahan diri kepada Allah atau berIslam dalam arti yang sebenarnya maka senada dengan Sayyid Hussain Nasr menganggap pendidikan Islam bukan untuk memperoleh kebahagiaan di dunia tapi adalah kampung abadi yaitu alam akhirat. ${ }^{24}$

\section{Makna Pendidikan Karakter Islam}

Sebelum membahas pendidikan karakter dalam Islam, perlu dicatat bahwa Islam adalah agama yang telah berumur 1400 tahun dengan misi utamanya untuk mengembangkan akhlaq individu. Nabi Muhammad Saw dengan jelas menuturkan bahwa “ Saya diutus tidak lain hnyaalah untuk menyempurnakan akhlaq " (alHadits). Jadi istilah pengembangan karakter sebenarnya telah ada jauh ssebelum istilah ini ditemukan di Barat padahal di Amerika saja tidak terdapat dalam literatur keilmuan Amerika sebelum tahun 1990 an. $^{25}$

Makna karakter itu telah terkandung dalam istilah akhlaq. Maka dari itu sebagai ganti pendidikan karakter mereka yang merujuk pada khazanah pendidikan Islam menggunakan istilah syahsyiyyah Islamiyyah (Islamic personality). Sebab kepribadian yang baik adalah aspek penting dalam keimanan dalam Islam. Kata akhlaqadalah jamak dari kata khulq artinya sifat dasar, watak, kebiasaan, prilaku. ${ }^{26}$

Menurut Arabic English lexicon, jamak dari khulq artinya sifat dasar (disposition), fitrah atau bentuk asas yang menjadi dasar penciptaan,

2. Nasr, Seyyed Hossein. 1984 "The Islamic Philosophers' Views on education." Muslim Education Quarterly 2 (4) : 516

${ }^{25}$ Salahuddin, Patricia Z “Character Education...” hal. 82

${ }^{26}$.Thomas Patrick Hugh, Dictionary of Islam, Munshirahm Manoharlal Publisher, Pvt Ltd, First Publised, 1885, New Delhi, 1995, hal 12 atau yang tepat lagi disebut sifat morak (moral character). Di kalangan oar ulama khulq difahami sebagai hakekat batiniyah manusia yanag baerupa akal jiwa dan kualitas-kualitas khusus dan sifatnya yang khusus seperti kebiasaan, tradisi, dan lain sebagainya. ${ }^{27}$ Ini berarti kata akhlak berkaitan dengan kata khalq yaitu bahwa sifat jiwa yang melekat (malakah) dakam diri seseorang sesuai dengan asal mula diciptakannya (ahsanu taqwim) yaitu fitrah. Jika jiwa manusia itu diciptakan Allah dengan fitrahNya (fitrallah allati fatarannas alaihi) maka berakhlaq adalah berfikir, berkehendak dan berprilaku sesuai dengan fitrah (nurani) Nya.

Imam al-Ghazali lebih detail lagi menjelaskan bahwa inti dari al-khulq atau aspek batiniyah manusia itu ada empat aspek yaitu : kekuatan ilmu, kekuatan marah, kekuatan syahwah dam kekuatan bertindak adil pada ketiga kekuatan itu. ${ }^{28}$ Agar dapat berlaku adil al-Ghazali menbandalkan akal sebagai pimpinanna. Tapi bagi Ibnu Taymiyayah yang dapat mengendalikan fitrah manusia adalah alQur'an ang id namakan fitrah munazzalah.

Fakhruddin al-Razi dalam kitab alNafswa al-Ruh, fi al-Akhlaq menyebutkan bahwa jiea manusia (nafs) terbagi menjadi tiga tingkatan. Pertama adalah mereka yan tenggelam dalam Nur Ilahi disebut alMuqarrabun. Kedua adalah mereka yang berorientasi ke langit dan terkadang ke bumi untuk urusn dunianya dan dinamakan alMuqtasidun atau golongan kanan (ashab alyamin). Terakhir, ketiga, dan terendah adalah

\footnotetext{
${ }^{27}$. E.W.Lane, Arabic English Lexicon, vol.1, Islamic Text Siciety, Cambridge, 1863, hal 801.

${ }^{28}$ Imam al-Ghazali, Ihya' Ulumuddin, Dar al-Kutub al'Ilmiyah, 1992, vol.1. 58-114
} 
yang tenggelam dalam cengkeraan hawa nafsu dan kenmaan jasmani, disebut al-Zalimin atau golongan kiri (ash al-Syimal). Ilmu untuk mencapai yang pertamaadalah olah batin (riyadah ruhaniyah). Ilmu untuk mencapai yang kedua adalah ilmu akhlaq. ${ }^{29}$ Makna akhlaq dilacak dari sumber perilaku manusia yang aql, ruh, nafs, qalb dan cara kerjanya.

\section{Pengertian pendidikan karakter.}

Perlu dijelaskan terlebih dahulu pengertian karakter sehingga dapat diketahui posisi atau perbandingan antara pendidikan karakter dengan pendidikan ahklag dalam islam . Devinisi karakter dalam kamus bahasa inggris. Dalam the new international comprehensive Dictionary of English Language Karakter diartikan sebagai berikut; 1 .The combination of qualities distinguishing any person or class of person.

2.Any distinntive mark or trait or such marks or trait collectivity, belonging to any person class, or race.

3.Individuality which is the product of nature ,habits and environment.

4. High qualities . 5. Moral force. ${ }^{30}$

Terjemahan bebasnya. 1). Kombinasi dari kualitas kualitas yang membedakan seseorang atau kelas seseorang . 2). Pertanda atau sifat yang berbeda atau tanda tanda atau sifat-sifat kolektif yang dimiliki seseorang, kelompok atau ras; 3). Kepribadian yang merupakan produk dari alam, kebiasaan dan

\footnotetext{
${ }^{29}$ Al-Razi, Fakhru al-Din, Kitab al-Nafs wa al-Ruh wa Sharh Quwahuma, edited by Dr. Muhammad Saghir Hasan alMa'sumy,Islamic Research Academy Islamabad 1968. ${ }^{30}$ The new international Webster comprehensive Dictionary of language . deluxe Encyclopedic Edition trident press International 1996 edition v.s 'charakter
}

lingkungan ; 4). Kualitas tinggi ; 5. Kekuatan moral.

Dalam kamus Collin Cobuild English Dictionary, "character" seseorang yang diartikan sebagai kepribadian, yang biasanya diakui dalam kaitannya dengan bagaimana mereka dapat dipercaya dan jujur. Orang berkarakter baik adalah orang yang dapat dipercaya dan jujur, demikian pula sebaliknya. Selain itu seseorang dianggap berkaracter apabila ia mempunyai kemampuan untuk menghadapi sistuasi sulit, tidak menyenangkan atau berbahaya. ${ }^{31}$

Menurut kamus Filsafat, character seseorang adalah ase jumlah sifat dasar perbuatan (termasuk berfikir dan berkata). Namun, Suatu perbuatan (secara lahiriah) berada di luar character jika tidak sesuai dengan watak yang dimiliki oleh seseorang, meskipun itu mungkin merupakan indikasi dari karakter yang lebih kompleks dari Nampak. ${ }^{32}$

Jika ketiga definisi character di atas disarikan maka dapat disimpulkan bahwa character adalah kualitas moral atau sifat dasar perbuatan seseorang yang terdiri dari sifat dapat dipercaya (reliable) dan sifat jujur (honest), atau kemampuan seseorang untuk menghadapi situasi sulit, tidak menyenangkan atau berbahaya.

\section{Unsur-unsur Karakter Inti}

Ketika ditanya tentang unsur-unsur apa saja karakter esensial yang penting harus ditanamkan kepada peserta didik, Thomas

\footnotetext{
${ }^{31}$ Collin cobuild English Dictionary, the university of Bermigham, Collin cobuild happer collin Publisher, London,1996

${ }^{32}$ Simon Blackburn, Oxford Dictionary of philoshopy, Oxford university Press, 1996, v.s. London, 1996
} 
Lickona menjawab dengan tegas ada 7 (tujuh) unsur, yaitu:

1. Ketulusan hati atau kejujuran (honesty)

2. Belas kasih (compassion)

3. Kegagahberanian (courage)

4. Kasih sayang (kindness)

5. Kontrol diri (self-control)

6. Kerja sama (cooperation)

7. Kerja keras (deligence or hard work)

Tujuh karater inti (core characters) itulah, menurut Thomas Lickona, yang paling penting dan mendasar untuk dikembangan pada peserta didik selain sekian banyak unsur-unsur karakter yang lain. Jika kita analisis dari sudut kepentingan restorasi kehidupan bangsa kita menurut istilah Ir. Sutawi, M. P, maka ketujuh karakter tersebut memang benar-benar menjadi unsur-unsur yang sangat esensial. Katakanlah unsur ketulusan hati atau kejujuran, bangsa saat ini sangat memerlukan kehadiran warga negara yang memiliki tingkat kejujuran yang tinggi. Membudayanya ketidakjujuran merupakan salah satu tanda dari kesepuluh tanda-tanda kehancuran suatu bangsa menurut Lickona.

Sebagai bahan mawas diri, konon tingkat kejujuran UN saja baru mencapai $20 \%$ ? Hal ini sudah tentu akan menjadi keprihatinan semua pihak. Mungkinkan kelemahan dalam hal ini yang menyebabkan terjadinya korupsi dan KKN di mana-mana?. Lebih dari itu, unsur karakter yang ke-7 adalah kerja keras (diligence or hard work). Konon nenek moyang bangsa kita dahulu dikenal sebagai bangsa yang rajin dan bekerja keras. Candi Borobudur dapat merupakan wujud dari kerajinan dan kerja keras bangsa ini di masa lalu. Sudahkah karakter inti ini sekarang ini sudah luntur.

Kini sebagian generasi muda kita malah justru mudah putus asa, lebih menyukai tangan di bawah ketimbang tangan di atas, lebih suka menyontek ketimbang harus belajar keras agar dapat memperoleh nilai yang tinggi dalam ujian? Selain kejujuran dan kerja keras, katakanlah unsur karakter yang ke-6 menurut Lickona, yakni kerja sama. Adakah kerja sama ini telah dapat kita kembangkan di rumah, sekolah, dan masyarakat? Dengan sedikit bergurau, kita sering memberikan contoh bahwa kelemahan utama tim sepak bola nasional kita sampai saat ini konon adalah karena tidak adanya kerja sama tim. Inikah gambaran karakter bangsa kita secara keseluruhan?

Selain tujuh unsur yang menjadi karakter inti menurut Thomas Lickona tersebut, para pegiat pendidikan karakter mencoba melukiskan pilar-pilar penting karakter yang menghubungan sinergitass antara keluarga, (home), sekolah (school), masyarakat (community) dan dunia usaha (business).

\section{Gambar 9 Pillar Penting Membangun}

\section{Karakter}

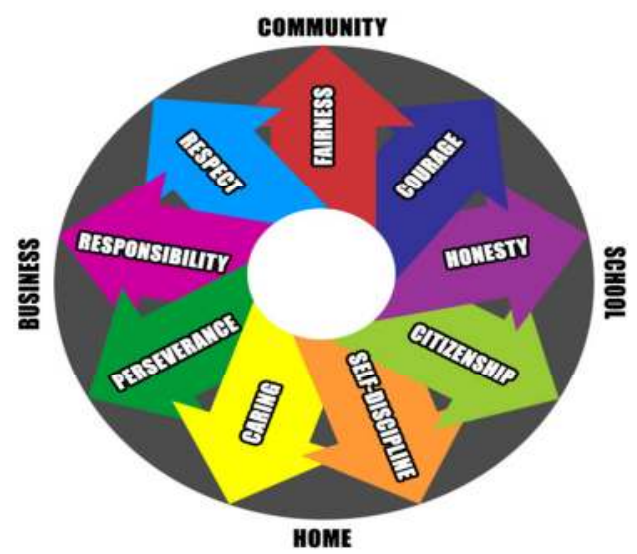


Sembilan unsur karakter dalam gambar tersebut meliputi unsur-unsur karakter inti (core characters) sebagai berikut:

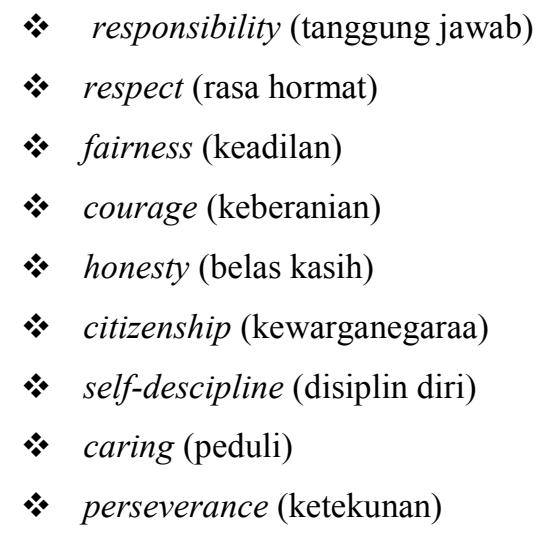

1). Religius, 2). Kejujuran, 3). Toleransi, 4). Disiplin, 5). Kerja keras, 6). Kreatif, 7). Mandiri, 9). Demokratis, 10). Rasa Ingin Tahu, 11). Semangat Kebangsaan, dan Cinta Tanah Air, 12). Menghargai Prestasi, 13). Bersahabat/Komunikatif, 14). Cinta Damai, 15). Gemar Membanca, 16). Peduli Lingkungan, 17). Peduli Sosial, 18). Tanggung Jawab

\section{Apa yang Harus Kita Lakukan?}

Sesungguhnya kita semua memiliki peran masing-masing untuk dapat melakukan pendidikan karakter, tentu saja sesuai dengan kedudukan, tugas, dan fungsi kita masingmasing. Yang diperlukan sejak awal adalah pemahaman tentang pentingnya pendidikan karakter tersebut, karena pendidikan harus dilaksanakan secara sadar dan terencana.

Sebagai diri pribadi, sesuai dengan prinsip pendidikan seumur hidup, kita harus menyadari dan meyakini bahwa kehadiran Nabi dan Rasul di muka bumi ini tidak ada lain kecuali memang untuk memperbaiki akhlak, dalam bahasa umum dikenal dengan karakter. Kita menyadari dan meyakini pentingnya pendidikan karakter terutama untuk kepentingan diri sendiri.

Selain itu, juga untuk saling ingat mengingatkan dengan sesama. Secara minimal, kita tidak menjadi bagian yang telah menyebabkan carut-marutnya kehidupan bermasyarakat, berbangsa, dan bernegara. Janganlah kita sampai kehilangan semangat dan kepedulian untuk secara sadar memupuk nilainilai karakter inti pada diri kita, dan menyampaikan kepada keluarga dan orang lain di sekitar kita.

Sebagai sebuah keluarga, kita memiliki kewajiban moral untuk menumbuh-suburkan, memupuk anak-anak dan keluarga kita dengan nilai-nilai karakter ini, mulai dari memberikan rasa kasih sayang kita kepada mereka. Konon, anak-anak sekarang sudah banyak kehilangan kasih sayang dari keluarganya, karena bapak dan ibunya telah banyak harus mencari sesuap nasi dengan bekerja dengan kondiri P7 (pergi pagi pulang petang, penghasilan pas-pasan). Bahkan, kekerasan dalam rumah tangga (KDRT) telah menjadi salah satu fenomena dalam kehidupan rumah tangga. Mencegah dan menghindari terjadinya tindak KDRT sudah barang tentu telah menjadi bagian yang dapat kita lakukan untuk melaksanakan pendidikan 
karakter. Proses pendidikan dalam keluarga ini dikenal dengan jalur pendidikan informal, yang menjadi pendidikan pertama dan utama dalam kehidupan manusia.

Sebagai warga dalam masyarakat, bangsa, dan negara, sudah barang tentu kita memiliki hak dan kewajiban. Sebagai warga dalam masyarakat, bangsa, dan negara, kita harus mematuhi hukum dan perundangundangan yang berlaku. Presiden Amerika Serikat yang dikenal amat dekat hubungannya dengan Bung Karno, John F. Kennedy, berpesan kepada bangsanya sebagai berikut:

"My fellow Americans, ask not what your country can do for you, ask what you can do for your country”. Bangsaku Amerika, janganlah tanya tentang apa yang dapat dikerjakan negara untukmu, tanyakan apa yang dapat Anda kerjakan untuk negara”.

Sebagai pendidik, atau tenaga kependidikan dalam satuan pendidikan formal dan nonformal, kita akan menjadi suri tauladan bagi peserta didik. Dalam hal ini, kita diingatkan oleh pepatah petitih yang ternyata memiliki nilai tinggi dalam pendidikan karakter ini. "Guru kencing berdiri, murid kencing berlari”. Untuk menjadi pendidik yang dapat ditauladani dalam proses pendidikan karakter, cara sederhana dapat kita lakukan. Sebagai contoh, melalui musik sederhana, kita dapat menitipkan nilai-nilai karakter di dalamnya. Dalam hal ini, Aristoteles mengingatkan bahwa

"Music has a power of forming the character, and should therefore be introduced into the education of the young."
Musik mempunyai satu kekuatan dalam pembentukan, dan karena itu akan dapat diperkenalkan dalam pendidikan bagi anak-anak dan generasi muda. Sebagai contoh, lagu "SatuSatu Aku Sayang Ibu" akan menjadi lagu pertama yang dikenal anak-anak kita di rumah dan di Kelompok Bermain, yang akan menjadi fondasi untuk memupuk dan mengembangkan karakter bagi anak-anak kita.

Sebagai tokoh masyarakat, pemimpin di level mana pun juga sudah barang tentu akan memiliki peran yang sangat besar dan penting dalam membangun karakter anak-anak bangsa. Seperti pendidik untuk satuan pendidikan, maka pemimpin pada level mana pun harus dapat menjadi suri tauladan bagi warga yang dipimpinnya. Pemimpin mempunyai tanggung jawab moral yang sangat besar mulai dari penentuan kebijakan, sampai dengan menjabarkan ke dalam program dan kegiatan operasional, serta memberikan pedoman atau acuan dalam pelaksanaan pendidikan karakter, agar dapat berjalan dengan lancar dan sukses.

\section{PENUTUP}

Dari uraian tersebut di atas, dapatlah diambil beberapa butir kesimpulan sebagai berikut:

- Pertama, karakter merupakan bagian penting dalam kehidupan manusia, yang telah membentuk jati diri manusia. Kita harus menyadari sepenuhnya bahwa kehadiran para Rasul dan Nabi diutus Tuhan Yang Maha Kuasa di muka bumi ini untuk memperbaiki karakter. Keberadaban suatu bangsa tergantung kepada tinggi rendahnya karakter bangsa itu sendiri. 
- Kedua, proses pembinaan dan pendidikan karakter harus menjadi usaha sadar dan terencana. Bahkan, "karakter tidak dapat dibentuk dengan mudah dan tenang. Hanya melalui pengalaman mencoba dan mengalami dapat menguatkan jiwa, menjelaskan visi, menginspirasikan ambisi dan mencapai sukses”. Demikianlah pesar Helen Keller (1880 1968), tokoh pendidikan usia dini kepada kita.

- Ketiga, konsep besarnation and character building pada zaman Sukarno, dan kemudian konsep besar pendidikan karakter yang telah diluncurkan Mendiknas pada acara peringatan Hari Pendidikan Nasional 2 Mei 2010 lalu haruslah dijabarkan ke dalam program dan kegiatan yang operasional yang jelas dan komprehensif, sehingga dapat dilaksanakan oleh semua pemangku pendidikan, dalam proses pengembangan dan pemupukan karakter, terutama kepada generasi muda.

- Keempat, semua dari kita, mulai dari diri sendiri, sebagai warga dari sebuah keluarga, warga masyarakat, bangsa, dan negara, pendidik dan tenaga kependidikan pada satuan pendidikan formal dan nonformal, sampai dengan para pemimpin dalam sem ua level mempunyai tugas dan tanggung jawab moral untuk dapat memahami (knowing), mencintai (loving) dan melaksanakan (implementing) nilainilai etika inti (core ethical values) dalam kehidupan pribadi dan masyarakat secara keseluruhan untuk membangun keberadaban bangsa yang bermartabat.

- Kelima, Setelah penulis mengadakan analisa ajaran agama yang dikembangkan adalah ajaran agama protestan yang memisahkan antara agama dan dunia sehingga pendidikan karakter ini telah suskses memisahkan hubungan manusia dengan Allah tapi berhasil menanamkan nilai individual dan sosial. Inilah pesan yang ditanamkan pendidikan karakter.Jika kita bandingkan tujuan pendidikan Nasional bangsa kita dalam UUD 1945 (Versi Amandemen) pasal 31 ,ayat 3 menyebutkan : Pemerintah mengusahakan dan menyelenggarakan satu sistem pendidikan nasional. Yang meningkatkan Keimanan dan ketakwaan serta ahklak mulia dalam rangka mencerdaskan kehidupan bangsa yang dianut dengan undang undang. Pasal 31 ayat 5 menyebutkan pemerintah memajukan ilmu pengetahuan dan teknologi dengan menjunjung tinggi nilai nilai agama dan persatuan bangsa untuk kemajuan peradaban serta kesejahteraan umat manusia. Demikian juga tujuan Pendidikan Nasionsl falsafah Undang Undang No 20 tahun 2003. UUD 1945 serta UU N0 20 tahun 2003. Sangat mencerminkan nilai Ketuhanan yang maha esa sebagai sila pertama dari pancasila karena kata sila pertama itu merupakan pengakuan bahwa dalam mengembangkan pendidikan bangsa ini tidak boleh lepas dari hubungan sesama manusia dan hubungan hamba dengan sang pencitpa yakni Allah swt. 


\section{DAFTAR PUSTAKA}

Leming, Jame S. (2008), “Theory. Research, and Practise In The Twentieth Century Character Education Movement", Journal Of Reseach in Character Education,6(2),

"Relegion and Character Education", (1999), The Phi Delta Kappa,81(1), hlm. 21$24,26-27$

Lickona, Thomas (1997), “ The Teacher's Role In character Education ", journal of Education, 179 (2)

Al-Attas, Syed Muhammad Al-Naquib. 1979. Aims and Objective of Islamic Education. Jeddah, Saudi Arabia : Hodder and Stoughton, (ISLAMIA, VOLUME 1X, No 1,2014.)

Nasr, Seyyed Hossein. 1984 "The Islamic Philosophers' Views on education." Muslim Education Quarterly 2 (4) :

Patrick Hugh, Thomas, Dictionary of Islam, Munshirahm Manoharlal Publisher, Pvt Ltd, First Publised, 1885, New Delhi, 1995 ,

E.W.Lane, Arabic English Lexicon, vol.1, Islamic Text Siciety, Cambridge, 1863

al-Ghazali, Imam Ihya' Ulumuddin, Dar alKutub al-'Ilmiyah, 1992, vol.1. 58-114

Al-Razi, Fakhru al-Din, Kitab al-Nafs wa alRuh wa Sharh Quwahuma, 1968, edited by Dr. Muhammad Saghir Hasan al-Ma'sumy,Islamic Research Academy Islamabad

The new international Webster comprehensive

Dictionary of language . deluxe Encyclopedic Edition trident press International 1996 edition v.s 'charakter
Collin cobuild English Dictionary, 1996, the university of Bermigham, Collin cobuild happer collin Publisher, London.

Blackburn, Simon, 1996, Oxford Dictionary of philoshopy, Oxford university Press, 1996, v.s. London.

Madjid, Abdul 2011, Pendidikan Karakter Perspektif Islam, Bandung: Rosdakarya

Koesuma A, Doni, 2010, Pendidikan Karakter: Strategi mendidika anak di Zaman Global Jakarta: Grasindo,

Muin, Fathul, 2011, Pendidikan Karakter: Konstruksi Teoritik dan Praktik (Jogjakarta: ArRuzz,

Franz Magnis Suseno, 1987, Etika Dasar, Jakarta: Pusat Filosof

Al Habsy, Husain, Kamus Al Kautsar,

(Surabaya: Assegaf, tt)

Katresna72, "Grand Design Pendidikan

Karakter" dalam Katresna72

Abdullah , M. Yatimi, 2007 Studi Akhlak dalam Perspektif Al Qur'an, Jakarta: Amzah, Muslich, Masnur, 2011, Pendidikan Karakter: Menjawab Tantangan Krisis Multidimensional, Jakarta: Bumi Aksara

Oos M. Anwar, 2010,Televisi Mendidik Karakter Bangsa: Harapan dan Tantangan dalam Jurnal Pendidikan dan Kebudayaan, (Jakarta: Balitbang Kementrian Pendidikan Nasional, Vol.16 Edisi Khusus III Oktober

Diakses pada 19-05-2015 . http://suparlan.com/18/2010/10/17/pen didikan-karakter-sedemikianpentingkah-dan-apa-yang-harus-kitalakukan/ 